\title{
USO DE PSICOFÁRMACOS POR MULHERES PRIVADAS DE
}

\section{LIBERDADE.}

Marleny Andrade Abreu, Universidade Federal de Campina Grande, (UFCG), marlennyandrade@ hotmail.com

Vanessa Estrela Rolim, Universidade Federal de Campina Grande, (UFCG), vanessaestrela@hotmail.com

Cícera Renata Diniz Vieira Silva, Universidade Federal de Campina Grande, (UFCG), renatadiniz_enf@yahoo.com.br

PALAVRAS-CHAVE: Mulheres aprisionadas. Psicofármacos. Saúde mental.

\section{INTRODUÇÃO}

Os psicofármacos são substâncias que atuam diretamente sobre o Sistema Nervoso Central (SNC) alterando a atividade psíquica, sendo utilizados no tratamento de diversos transtornos mentais. A pesar de indispensáveis no tratamento de diversos problemas de saúde, os psicofármacos alteram a atividade psíquica, a percepção e o pensamento, podendo ainda causar dependência e, por conseguinte, influenciar no comportamento psicossocial do indivíduo. Andreoli et al., (2012), afirma que há uma prevalência mais elevada de transtornos mentais na população prisional do que na comunidade. A população carcerária feminina é cinco vezes mais propensa a ter um problema de saúde mental do que mulheres da população em geral. Neste contexto fica evidente que as doenças mentais relacionadas às prisioneiras torna-se um problema de saúde e segurança pública mundial, que necessita de uma atenção especial das equipes de saúde. Esse estudo tem o objetivo de avaliar o uso de psicofármacos pelas mulheres da cadeia da cidade de Cajazeiras-PB.

\section{METODOLOGIA}

Estudo abordagem quantitativo, do tipo descritivo-exploratório, documental aliado à coleta de dados em campo. Os dados foram coletados na cadeia pública do município de Cajazeiras-PB. A amostra foi composta por 30 mulheres que se encontravam encarceradas. A amostra é do tipo não probabilística intencional. O instrumento de coleta de dados se deu por um questionário que continha perguntas fechadas referentes à temática em questão. $\mathrm{O}$ 
questionário foi aplicado no mês de janeiro de 2015. A coleta foi realizada nas dependências da cadeia municipal, no horário de funcionamento do serviço. Os dados foram analisados através de estatística descritiva, sendo estes organizados, tabulados e analisados no programa estatístico Statistical Package for the Social Sciences (SPSS), versão 21.0. O estudo obedeceu às diretrizes da Resolução $N^{\circ}$ 466/2012 do Conselho Nacional de Saúde (CNS) que regulamenta pesquisas envolvendo seres humanos. Para isso, houve a solicitação prévia de autorização do estudo junto às Secretarias Municipais de Saúde dos municípios.

\section{RESULTADOS E DISCURSSÕES}

O uso de substâncias psicoativas prevaleceu entre a maioria das mulheres, 76,4\% consumiam algum tipo de psicofármaco. $\mathrm{O}$ isolamento social, a pobreza, o desemprego e a falta de perspectiva no sentido de melhorar economicamente, em geral, trazem sentimentos de angústia, revolta, preocupações e desânimo. Esses fatores provocam agravos à saúde mental das pessoas que, muitas vezes, fazem uso de psicofármacos numa tentativa de aliviar seu sofrimento (FIGUEIRÓ et al. 2015).

Na situação conjugal, predominou as mulheres que não tinham um parceiro com 63,3\%. O estado civil é um fator importante que está frequentemente associado ao uso de substâncias psicoativas. As mulheres solteiras que apresentaram maior predomínio na pesquisa são mais propensas a desenvolverem algum tipo de transtorno mental e dependência química (RODRIGUES et al,. 2006).

O tempo mínimo de consumo de psicofármacos observado foi de um mês e o máximo chegou a 360 meses. Cerca de 52,2\% afirmaram que faz uso desses medicamentos a mais de três anos e apenas 4,3\% afirmou que faz uso a menos de um ano. $\mathrm{O}$ uso contínuo dessas substâncias por períodos prolongados aumenta as chances de dependência e tolerância, além de potencializar os efeitos colaterais e provocar reações adversas (BOTEGA, 2017).

...o adoecer mental é a consequência da destruição da trama de sustentação da continuidade do eu e devido a isto dissolve-se sua vivência de existir. Concretiza-se um vazio insuportável e, ao buscar saídas, constitui-se uma nova trama de sustentação e continuidade, e constrói-se um novo projeto, mas, desta vez, pouco ou nada compartilhado com os demais, pois a pessoa poderá armar um eu fechado e solitário, desestruturando-se a leitura prospectiva de sua ação. (Humerez, 2000, p. 60). 
O uso contínuo substâncias psicoativas por períodos prolongados aumenta as chances de dependência e tolerância, além de potencializar os efeitos colaterais e provocar reações adversas. Vale salientar que o uso por longos períodos é indicado apenas em casos graves de transtornos mentais (RIBEIRO, 2009).

Os psicofármacos mais utilizados foram o antidepressivo Amitriptilina com 47,5\% e o ansiolítico Diazepan 40,0\%. O número de detentas que relataram ter tido algum efeito colateral atingiu 60,9\%. Os principais efeitos relatados foram sensação de boca seca e sonolências, ambas correspondendo a 23,8\% e 19,0\% afirmaram sentir taquicardia. Tremores, cansaço, agitação e irritação aprecem em menor proporção. O grande percentual de efeitos colaterais pode estar relacionado ao fato do tempo prolongado e contínuo do uso dessas substâncias. Apesar de serem eficazes e produzirem efeitos benéficos, os psicofármacos quando utilizados inadequadamente podem levar ao surgimento de efeitos indesejáveis (MOURA et al., 2016).

\section{CONSIDERAÇÕES FINAIS}

O consumo inadequado de psicofármacos é considerado um problema de saúde pública que vem crescendo mundialmente e repercute em problemas que envolvem toda a sociedade, necessitando assim de ações eficazes que venham reduzir esse problema e minimizar seus agravos. No estudo, o consumo de psicofármacos entre as mulheres encarceradas é uma prática comum e incontestável. Observa-se uma grande vulnerabilidade nas mulheres encarceradas no que diz respeito à ocorrência de transtornos mentais e consumo de substâncias psicoativas. A privação da liberdade, o isolamento social e o distanciamento da família ampliam as chances de surgimento de problemas psicológicos e aumentam o consumo inadequado de fármacos dentro da cadeia. Diante desses fatos, percebe-se a importância da realização de programas de prevenção e intervenção nessa área nos presídios.

\section{REFERÊNCIAS}

ANDREOLI, S.B.; ABDALLA-FILHO, E.; SANTOS, M.M.; MARQUES, C.M.; TABORDA, J.G.V. Transtorno Mental e Prisão. In: TABORDA, J.G.V.; ABDALLAFILHO. E.; CHALUB, M., organizadores. Psiquiatria Forense. $2^{\mathrm{a}}$ ed. Porto Alegre: Artmed; 2012. p. $585-597$ 
FIGUEIRÓ, R.A.; MAGDA, D.; DELANNO, A.; GERLÂNDIO, M. Consumo de Medicação Psicotrópica em uma Prisão Feminina. Rev. Psicologia política. VOL. 15. No 34. PP. 531546. SET. - DEZ. 2015

BOTEGA, N.J.; NOGUEIRA-MARTINS, L.A. Interconsulta psiquiátrica: formação profissional e organização de serviços. In: BOTEGA NJ (org) Prática psiquiátrica no hospital geral: interconsulta e emergência. Porto Alegre : Artmed Editora, 2017

HUMEREZ, D.C.; (2000). História de Hélia: referência existencial da esquizofrenia paranóide. Acta paulista de Enfermagem, 13(1), 55-65.

MOURA, D.C.N.; PINTO, J.R.; MARTINS, P.; PEDROSA, K.A.; CARNEIRO, A.G.D. Uso abusivo de psicotrópicos pela demanda da estratégia saúde da família: revisão integrativa da literatura. SANARE, Sobral - V.15 n.02, p.136-144, Jun./Dez. - 2016

RIBEIRO, W.S.; ANDREOLI, S.B,.; FERRI, C.P.; PRINCE, M.; MARI, J.J. Exposição à violência e problemas de saúde mental em países em desenvolvimento: uma revisão da literatura. Rev Bras Psiquiatria. 2009;31(Suppl 2):S49-57.

RODRIGUES, M.A.P.; FACCHINI, L.A.; LIMA, M.S. Modificações nos padrões de consumo de psicofármacos em localidade do Sul do Brasil. Revista de Saúde Pública, São Paulo, v. 40, n. 1, p. 107-114, dez./2006. 